\title{
COLLISION AVOIDANCE AT NONTOWERED AIRPORTS
}

\author{
Teresa Ann Sloan \\ Central Washington University
}

\begin{abstract}
From January 1 of 1988 to December 31 of 1998 there were an average of 16.9 midair collisions and 17.7 fatalities per year involving general aviation aircraft in the United States (Carter, 1999). In February of 2000 alone there were five midair collisions (NTSB, 2000). Most midair collisions occur in the traffic patterns of non-towered airports and on final approach. What can a general aviation pilot do to reduce the risk of a midair collision at a non-towered airport? What are the FAA's and Transport Canada's recommended procedures for traffic patterns? What alternative procedures are currently in use by pilots and are they safe? A review of the regulations, advisories, and various articles on the subject, a survey of flight instructors on the methods taught to enter such patterns, and a discussion of legal precedents and certificate actions will aid the pilot in choosing a method for pattern entry at non-towered airports.
\end{abstract}

\section{INTRODUCTION}

According to figures from the National Transportation Safety Board (NTSB), during the period from January 1, 1988 to December 31, 1998 there were approximately 16.9 midair collision accidents per year involving general aviation aircraft in the United States (L. Carter, NTSB, personal comm-unication, August 13, 1999). According to Carter, the number of fatalities averaged slightly above one per accident. February of 2000 proved to be a disastrous month with five midair collisions, three of which occurred during a two day period, involving five fatalities (NTSB, 2000). A study by the Aircraft Owners and Pilots Association (AOPA) Air Safety Foundation showed that nearly half of these midair collisions occurred while in, approaching, or departing a traffic pattern (AOPA, 1998). Furthermore, many of these accidents occurred during good weather, at non-towered airports, and on or near final approach (AOPA, 1998; Duncan, 1997; Landsberg, 1997).

According to the Trans-portation Safety Board of Canada (TSB), during the period from 1989 to 1998 there were 31 collisions between airplanes in Canada. Of these 31 collisions, 20 occurred in the air and 11 involved aircraft on the ground. Of the 31 total collisions, 28 involved general aviation aircraft. Of the 31 collisions, 7 occurred during take-off, approach, or landing (TSB, 1997).

The number of collisions and fatalities at non-towered airports indicates that there is room for improvement in the area of safety regarding the procedures for operating at such airports. A review of the regulations, advisories, and various articles on the subject, a survey of flight instructors on the methods taught to enter such patterns, and a discussion of legal precedents and certificate actions will aid the pilot in 
choosing a method for pattern entry at nontowered airports.

\section{LITERATURE REVIEW}

\section{Regulations}

According to the Code of Federal Regulations (CFR, commonly known to pilots as FARs) 14 CFR 91.126 (b)(i) (1991) states that when approaching to land at a non-towered airport all turns shall be made to the left (except at those airports displaying right hand patterns). The regulation does not specify at which point of the traffic pattern pilots must enter, nor does it specify the procedure for exiting the pattern. 14 CFR 91.103 (2000) pertains to preflight action and states that before any flight, other than one remaining in the local area, pilots shall familiarize themselves with all available information. This includes checking the Airport/Facility Directory (A/FD) or other commercial publication for information regarding traffic pattern direction and traffic pattern altitude (TPA).

The Canadian regulations are similar. Canadian Air Regulation (CAR) 602.96 (3) states, "The pilot-in-command of an aircraft operating at or in the vicinity of an aerodrome shall [emphasis added] (a) observe aerodrome traffic for the purpose of avoiding a collision; (b) conform to or avoid the pattern of traffic formed by other aircraft in operation; (c) make all turns to the left when operating within the aerodrome traffic circuit, except where right turns are specified by the Minister in the Canada Flight Supplement;...(e) where practicable, land and take off into the wind unless otherwise authorized by the appropriate air traffic control unit; (f) maintain a continuous listening watch on the appropriate frequency..." (Transport Canada, 1996). Note that the Canadian regulations are slightly more specific than the US regulations. The pilot is also directed to observe the flow of traffic, land into the wind, and utilize the radio.

\section{Variants for Traffic Patterns}

One reason the regulations and advisories are not more restrictive is the number of variants to traffic patterns. For instance, the TPA may not be the same for all aircraft operating in the traffic pattern. Some nontowered airports that cater to both small, general aviation aircraft and larger twin engine or turbine aircraft may have one TPA for slower aircraft and a higher TPA for faster aircraft (Federal Aviation Administration [FAA], 1993). Furthermore, the available altitude above TPA in which a pilot may overfly the airport may be restricted by overlying airspace (such as Class B airspace).

If helicopters are present at the airport, they may fly a pattern similar to the fixed wing pattern but at a lower altitude (500 feet above ground level [AGL]) and closer to the runway. The only stipulation in 14 C.F.R. 91.126 (b) for helicopters is that they avoid the flow of fixed wing aircraft when approaching to land (FAA, 1991). This means that in addition to being lower and closer, the helicopter pilot may choose to fly the pattern on the opposite side of the runway from the fixed wing traffic (FAA, 1993).

If gliders are present, their traffic pattern is inside the powered aircraft pattern. Some airports have an established Glider Operating Area on one side of the runway. Extreme caution must be exercised at these airports. According to Advisory Circular (AC) AC90-66A the glider pattern will normally be on the same side of the runway as the Glider Operating Area (FAA, 1993). For instance, if Runway 9 and 27 both have standard left hand traffic for powered aircraft and a Glider Operating Area exists 
on the north side of the runway, the powered aircraft will be operating south of the runway when Runway 27 is in use, and the gliders will be operating north of the runway with right hand traffic. Add a helicopter to the scenario and chaos can erupt.

A glaring example of an airport rife for multiple patterns is Ephrata, Washington. According to Jeppesen's Airway Manual Services Northwest United States Airport Directory, Washington 10 (Jeppesen, 1999), Ephrata Municipal airport has two runways: runway $02 / 20$ and runway $11 / 29$. The TPA for fixed wing aircraft is 800 feet AGL and for ultralights is 250 feet AGL. Runway 2 has right traffic. The remarks contain the following:

Birds in the vicinity

Airplane use of runway 11 is discouraged due to glider operations

Agricultural aircraft in area

Heavy glider activity from April through October

Ultralight activity in area

Aerobatic activity over center of airport

Navy aircraft carrier deck is painted on the runway

There was a midair collision at this airport on August 1, 1993 between a student pilot on a solo flight in a Cessna 150 and a Grumman 164B cropduster (NTSB, 2000). The collision occurred while the Cessna 150 was on final approach for runway 2 . The cropduster had entered the airport environment from the north (the same side as the appropriate right hand pattern for runway 2) and was spraying chemicals on the edge of the runways. There were conflicting reports regarding whether or not the Grumman pilot radioed position reports on the common traffic advisory frequency (CTAF).

\section{Determining the Traffic Pattern}

The best way for a pilot to determine the direction of a traffic pattern for a particular runway is to look up the information in the A/FD. The A/FD provides information about public airports including direction of turns and traffic pattern altitudes. If a runway has nonstandard right hand traffic, the reason (such as obstacles or a noise sensitive area) will often be given. Several other commercial and state publications are also available which provide the same information as the A/FD.

14 CFR 91.103 states, "Each pilot in command shall, before beginning a flight, become familiar with all [emphasis added] available information concerning that flight" (FAA, 2000). The term "all available information" implies checking on the traffic pattern, including direction of turns and traffic pattern altitude, for the intended airport. It should be noted that not all publications include the traffic pattern altitude. If no altitude is shown, the Aeronautical Information Manual (AIM) Part 4, Section 3, Paragraph 4 recommends 1,000 feet AGL (FAA, 1999).

The AIM describes various aids that can help the pilot determine the most appropriate runway and the direction of the traffic pattern. Nowhere in the FARs or the AIM is there a suggested procedure for how to overfly an airport to check on these aids. The AIM (FAA, 1999) in chapter 4, Section 3 , Paragraph 4 does state that "... pilots of enroute aircraft should be constantly on the alert for other aircraft in traffic patterns and avoid these areas whenever possible." This paragraph also states that most traffic pattern altitudes extend from 600 feet AGL to 1500 feet AGL, and occasionally when military turbojet aircraft are present the pattern may be as high as 2500 feet AGL. Furthermore, AIM chapter 4, Section 1, Paragraph 9 
(FAA, 1999) details the recommended procedures for communication on the CTAF for non-towered airports, including reporting when inbound from 10 nautical miles out.

\section{Entering the Pattern}

14 CFR 91.126 (FAA, 1991) states that when approaching to land all turns shall be made to the left (or right if the runway displays approved signals or markings). This regulation does not specify how many legs in the pattern must be flown nor at what point the pilot should enter the pattern. According to Duncan (1997) of the FAA, the procedures are only recommended and are not more specific in order to give pilots some flexibility because of "changing wind conditions, intrusion of other traffic, and other possible emergencies...". For example, an airport layout may be such that a pilot suspects mechanical turbulence on the pattern side of a runway. In that case a straight in approach or base entry may bypass the turbulence.

The AIM, Chapter 4, Section 3, Paragraph 4 (FAA, 1999) diagrams the recommended procedure for entering a traffic pattern (see figure 1). The recommended entry is on a 45 degree angle (the 45) to the downwind. Note that for most airports the 45 has the approach end of the runway at the apex of the angle. This allows the pilot to enter the downwind leg at approximately midfield. If the runway is very long (over 4000 feet) the aim point will be upwind of the approach end in order for the aircraft to arrive on the downwind leg at the midpoint of the runway. Many new and even experienced pilots aim at a 45 degree angle to the midpoint of the runway, which is hazardous as it puts the pilot in potential conflict with aircraft on the crosswind leg or exiting on the 45. Although the AIM stipulates that the pilot should be at TPA when entering the downwind leg (FAA,
1999), this can lead to some confusion: should the pilot be at TPA at the point where the turn is made from the 45 to downwind or prior to that point when on the 45 degree entry itself? Advisory Circular AC 90-66A is a little more specific. It states that once "... the proper traffic pattern direction has been determined, the pilot should then proceed to a point well clear of the pattern before descending to the pattern altitude" (FAA, 1993). The prudence of descending to TPA away from the traffic pattern can be seen by imagining the scenario of a high winged aircraft already established on the 45 at TPA and a low winged aircraft above it descending to TPA. Such a scenario is a perfect setup for a midair collision.

The Canadians approach traffic pattern entries somewhat differently. Although Canadian Air Regulation (CAR) 602.96 (3)(c) also specifies making "all turns to the left when operating within the aerodrome traffic circuit, except where right turns are specified," the similarities stop there (Transport Canada, 1996). The Canadian Aeronautical Information Publication (AIP) contains provisions for entering the circuit from the upwind side (Transport Canada, 1999). Furthermore, the AIP distinguishes between circuit entries for airports in a mandatory frequency (MF) area (an area of sufficient traffic to warrant requirements for communication) and those not in an MF area. According to AIP Rules of the Air (RAC) 4.5.2.(a)(v) and (vi) (Transport Canada, 1999), when operating within an MF area where the airport advisory information is available over the radio, the "aircraft may join the circuit pattern straight in or at 45 degrees to the downwind leg, or straight in to the base or final legs." If the aircraft is in an MF area where airport advisory information is not available or at an aerodrome not within an MF area, the "aircraft should approach the traffic circuit from the upwind leg, or, once 
having ascertained without any doubt that there will be no conflict with other traffic entering the circuit or traffic established within the circuit, the aircraft may join the circuit on the downwind leg" (Transport Canada, 1999). Referring to figure 2, note that the downwind entry is made straight in to downwind and not at a 45 degree angle (Transport Canada, 1999, figure 4.6). AIP RAC 4.5.2 (a)(ii) states that "unless otherwise specified or required by the applicable distance from cloud criteria, aircraft should join the downind leg, or enter the crosswind at an altitude of 1,000 feet AAE (above aerodrome elevation.) When joining from the upwind side, plan the descent to cross the runway in level flight at 1,000 feet AAE or the published circuit altitude. Maintain that altitude until further descent is required for landing" (Transport Canada, 1999).

\section{Upwind Entries}

For years there has been an ongoing argument regarding the necessity of entering the traffic pattern at a non-towered airport on the recommended 45 degree to downwind entry. Some pilots have long argued that the regulations state only the direction of turns and do not prohibit zero degree to downwind entries, base entries, straight in approaches, or crosswind entries from the upwind side of the runway. In "The Great Debate" (Landsberg, 1997), published by the AOPA's Air Safety Foundation, Landsberg described an alternative method for entering the traffic pattern from the upwind side. In this method, the pilot enters the upwind leg at pattern altitude, crosses over the runway near the midfield point, and turns to the downwind leg. At the time the article was published, Landsberg stated that "there was consensus within the FAA to allow the upwind entry as an alternate way to get onto the downwind leg. The negotiated settlement was that upwinders should yield to aircraft on the downwind or about to enter downwind from the normal 45-degree entry point" (Landsberg, 1997).

Michael Henry, the FAA's Washington, D. C. manager of the General Aviation and Commercial Division for Flight Standards, reported that the upwind entry method is currently under review by the FAA and a new advisory circular regarding pattern entries at nontowered airports is being drafted. He stated that the FAA personnel working on the advisory circular have not yet reached consensus regarding the upwind entry method. According to Henry, acceptance or rejection of the upwind entry method "goes back to the Law of Primacy." Pilots who were initially taught by their instructors that an upwind entry method was inherently dangerous were against it. Those pilots whose instructors taught the upwind entry method thought that it was safe" (M. Henry, personal communication, April 5, 2000).

Proponents of the upwind entry method argue that this method had been successfully used in Canada. In Canada, the upwind entry is an established procedure and is taught to student pilots from the beginning of their training. This substantiates Henry's statement regarding the Law of Primacy. Furthermore, the fact that there are significantly fewer licensed pilots and aircraft operations in Canada must also be considered.

There is one aspect of the Canadian upwind entry recommendation that calls for concern. AIP RAC 4-3-2 (a)(ii) states that the pilot should be at circuit altitude prior to entering the crosswind leg (Transport Canada, 1999). In this respect, the Canadian AIP is similar to the US AIM in that neither publication addresses how or where the pilot should descend to circuit altitude/TPA. Since the AIP shows no procedure for the 
descent to circuit altitude prior to being established on the upwind approach to the crosswind, several aircraft could be converging on the same point with the possibility of higher aircraft descending into lower aircraft.

\section{DISCUSSION}

\section{How Flight Instructors Teach Pattern Entries}

The method used by a pilot to enter the traffic pattern at a non-towered airport is included in the pilot's initial flight training. A survey of flight instructors showed the diversity of methods currently being taught, especially the methods used for an upwind entry and the potential for conflicts in traffic patterns.

\section{Method}

Participants. 78 flight instructors responded to the survey. The instructors were attending Flight Instructor Refresher Courses (FIRCs) sponsored by the Washington State Department of Transportation, Aeronautics Division. The first FIRC was held in November of 1999 and the second was held in January of 2000. Both FIRCs were held in western Washington state. The population was a convenience sampling; volunteers who wished to participate returned completed surveys after FIRC sessions.

Materials. 100 surveys (50 at each FIRC) were distributed randomly to participants during registration periods. The surveys requested instructors to diagram how they taught their students to enter the traffic pattern at a non-towered airport. The survey included a sketch of a runway with a segmented circle displaying standard left hand traffic and a wind direction indicator.
The instructors were asked to describe how they teach (1) entering the pattern when arriving on the same side of the airport as the pattern and (2) entering the pattern when arriving from the side opposite the pattern.

Results. The surveys showed that the majority of the respondents teach according to the recommendations of the AIM and AC 90-66A. The survey results are tabulated in Table 1.

There were three primary methods described by the instructors. The first method entailed overflying the airport from the upwind side to maneuver to the 45 (see figure 3). The second method involved turning to the downwind after crossing over the airport at TPA (see figure 4). The third method was to avoid the traffic pattern completely and maneuver to enter on the standard 45.

Of the seventy-eight respondents, forty-three chose method one, although there were some differences in how the respondents described the method. Twentyfour respondents stated they would overfly the airport at TPA +500 feet, thirteen respondents stated they would overfly the airport at TPA + 1000 feet, and another six respondents chose an altitude other than TPA +500 or +1000 feet. Twenty-one of the seventy-eight respondents chose the upwind entry method. Nine of those respondents chose to cross over the runway near the approach end of the runway and twelve of them chose to cross at midfield. Twelve of the respondents chose either a variation of the overflight or upwind methods and two depicted entering on the 45 with no indication of how they would maneuver to that position. Additionally, four respondents misunderstood the instructions and did not answer appropriately. Note that there were eightytwo responses from the seventy-eight respondents. This discrepancy was due to four respondents who listed both an 
overflight method and an upwind entry method.

The survey showed some frightening trends. Eight of the twelve responses classified as variations depicted flying outbound on a 45 degree angle from the approach end of the runway while descending to TPA. Such an approach would be in serious danger of a collision with an aircraft climbing out and following the procedure recommended by AC 90-66A (FAA, 1993). Two of the variation responses depicted the overflight method but showed a descent while inbound on the 45 degree entry. Due to the blind spot ahead of and below an aircraft, such an approach could result in a descent into traffic already established on the 45 at TPA. Finally, two of the variation responses depicted upwind entries while descending to TPA. This method could also result in a blind descent into traffic already established at TPA.

\section{Legal Ramifications}

Pilots must consider the legal ramifications of entering the pattern in a nonstandard fashion. Any pilot who enters the traffic pattern in opposition to the direction of turns established in the A/FD (and now shown for most airports on the sectional chart) may be faced with a violation of 14 CFR 91.126 (b)(1) (FAA, 1991).

Precedence has already been established in this matter when two airline pilots sustained certificate action regarding the manner in which they approached a nontowered airport. (Yodice, 1995). In both incidents the pilots were conducting approaches to the nontowered airport at Kotzebue, Alaska. The first incident involved a captain of an air carrier making a right turn onto final from approximately three miles out. Another aircraft was approaching the runway from a VOR/DME approach and both aircraft had to alter course. The FAA cited the captain with a violation of 14 CFR 91.89 (now known as 91.126) and suspended his Airline Transport Pilot (ATP) license for 20 days (Yodice, 1995).

The second incident involved a captain also executing a right turn to final. The captain stated that he made the turn to final approximately four miles out, which then constituted a straight in approach. This captain was also cited with a violation of 14 CFR 91.89 (now 91.126) and his ATP certificate was suspended for 25 days. The captain appealed the suspension to the NTSB. An NTSB law judge found that the turn was made much closer to the airport, between one to two miles out, and therefore constituted a right hand turn approaching to land. The captain then appealed to the full Board but the suspension was upheld (Yodice, 1995).

These two incidents set important precedents of which pilots should be aware. First, a turn to final from one to two miles away from the airport does not constitute a straight in approach. Second, regardless of how far out a straight in approach is initiated, "it must not interfere with aircraft in the traffic pattern or on an instrument approach" (Yodice, 1995). Furthermore, should a collision occur as the result of an aircraft NOT following the procedures recommended by AC 90-66A (FAA, 1993), the pilot (should he or she survive) may be faced with a hefty lawsuit.

There have been several court cases that resulted in findings regarding the use of the AIM and ACs. The first case, Associated Aviation Underwriters and Fidelity and Casualty Company of New York v. United States of America (1979), resulted in a judgment that stated, "A pilot must have studied and must know provisions of [sic] Airmen's Information Manual and 
Federal Aviation Authority advisory circulars pertaining to his flying activities and, furthermore, is charged with that knowledge of those facts which were then material to the safe operation of his flight."

The second case, Brenda Mallen, as widow of Steven Mallen v. United States of America (1979), resulted in a judgment stating, "In negligence action, airman's information manual and FAA advisory circulars are admissible as competent evidence of practices customarily followed by pilots, as it relates to standard of care."

The third case, referred to as In re N500L CASES Civ. No. 78-2126 (1981), resulted in a judgment stating, "Information contained in FAA advisory circulars ... is chargeable to all certified pilots and is evidence of standard of care..."

The most incriminating judgment regarding traffic pattern entries resulted from a fatal midair collision (MAC) at a non-towered airport at Greenwood, Indiana. In this case, referred to as In re Greenwood Air Crash (1995), the judgment included a statement that the " pilot initiated [sic] nonstandard right-hand turn and decided to obtain his Instrument Flight Rules (IFR) clearance at [sic] critical time in take off, while still climbing away from [sic] airport, [sic] increased his duty to be vigilant to see and avoid other aircraft." If the thought of a midair collision does not frighten all pilots into compliance with required and recommended procedures, perhaps the thought of certificate action, lawsuits, and financial ruin will.

\section{Risk Reduction}

There are numerous ways a pilot can reduce the risk of a midair collision at a nontowered airport. First, the pilot should follow 14 CFR 91.103 and become familiar with all available information regarding the intended airports to be used (FAA, 2000).
The pilot should check the A/FD, review any Notices to Airmen (NOTAMs) for the area, and, if any questions or doubts exist, call the phone number listed in the A/FD for the airport manager or fixed base operator (FBO).

Second, the pilot should use the radio as recommended in the AIM (FAA, 1999) and in AC 90-42F (FAA, 1990) and listen for other aircraft in the area. When arriving at a non-towered airport, the CTAF (shown on aeronautical charts and in the $\mathrm{A} / \mathrm{FD}$ ) should be monitored within 10 miles of the airport (or as soon as possible when on an instrument flight plan). If flying an aircraft without an installed radio, one should consider investing in a hand-held radio. They provide an inexpensive form of insurance and are well worth their cost in terms of risk reduction.

Third, the pilot should maneuver the aircraft so as to enter the pattern on the 45 to downwind. Until such time as the FAA publishes an advisory circular describing an upwind entry method, aircraft approaching the airport from the opposite side of the pattern should plan to overfly the airport at an altitude appropriate for the activities and the TPAs of the airport and maneuver onto the 45. The survey of Washington State flight instructors showed that their preferred method of maneuvering to the 45 was to:

a. fly directly over the center of the runway on a perpendicular course and at an altitude above TPA,

b. fly outbound until well clear of the traffic pattern, begin the descent, turn 90 degrees toward the upwind direction, and

c. maneuver so as to enter on the 45 to downwind after reaching TPA. 
If the pilot is unable to determine the active runway by using the radio prior to reaching the airport, the same method may be used to overfly the segmented circle and wind direction indicator to ascertain the active runway and pattern direction before entering the pattern.

Fourth, the pilot should be aware of any variant traffic patterns that may be in concurrent use, such as ultralights or gliders. Once again, a check of the A/FD, a call to the airport manager or FBO, or careful monitoring of the CTAF can warn the pilot of such activities. This knowledge can help the pilot to understand where possible conflicting traffic might appear. If glider activities are encountered, the pilot should also refer to 14 CFR 91.113 regarding rightof-way rules (FAA, 2000).

Fifth, when taking off and remaining in closed traffic, the pilot should adhere to the following recommendations for maneuvering from AC 90-66A (FAA, 1993):

a. The pilot must ascertain that there is no conflicting traffic prior to taxiing onto the runway. If the taxiway or runup area allows, a 360 degree turn can be made to check the final approach course and traffic on base from either direction. Long delays on the runway or taxiing into position and holding should be avoided as the potential for collision is greatly increased.

b. On departure, the pilot should climb straight ahead until reaching an altitude of at least TPA minus 300 feet so that pattern altitude will be reached prior to turning to downwind. This enables the pilot to have the nose lowered to the level flight attitude on downwind, which greatly improves the pilot's ability to see other aircraft at the same altitude on downwind.

c. If a go-around has been executed, the pilot should continue upwind until reaching the end of the runway, even if pattern altitude or TPA minus 300 feet has been reached prior to that point. This will prevent a premature turn to crosswind that might not be expected by other aircraft in the pattern.

d. On downwind, TPA should be maintained until at least abeam the approach end of the landing runway. The base leg should be turned at a point that is approximately 45 degrees between the tail of the aircraft and the runway; however, this point is varied depending on wind and the traffic ahead in the pattern.

Sixth, when taking off and departing the airport traffic pattern, pilots should follow the recommendation of AC 90-66A (FAA, 1993) and continue straight ahead or exit with a 45 degree turn toward the traffic pattern after passing through TPA. Although the CFRs, the AIM, and AC 90$66 \mathrm{~A}$ do not specify when a turn back towards the airport may be made, common sense dictates that it would be less than prudent to turn back towards the airport prior to reaching an altitude above other aircraft in the pattern.

Seventh, it is important to remember that the AIM (FAA, 1999, Chapter 4, Section 3, Paragraph 4) states, "Traffic pattern altitudes should be maintained unless otherwise required by the applicable 
distance from cloud criteria (FAR 91.155)." This means that during marginal visual flight rules (VFR) conditions, the pilot must be familiar with the National Airspace System and the type of airspace located at the airport of intended use (FAA, 1999). In marginal VFR conditions this could require flying the pattern at an altitude below normal TPA. If this does not sound appealing, perhaps waiting for a day with better weather conditions would be a better choice.

Eighth, when instrument traffic is in operation, the instrument pilot and other aircraft in the pattern must be aware of each other. Since the A/FD does not show instrument approaches, familiarity with instrument approach vocabulary and careful monitoring of the CTAF can warn the VFR pilot of IFR activity. The VFR pilot should understand that in minimum VFR conditions, the instrument pilot might be trying to transition from an instrument scan to an outside visual scan upon breaking through the clouds. Instrument pilots should understand that during operations at nontowered airports their final approach segment may not be congruent with the VFR pattern. This means that an instrument pilot on an approach to a runway other than the one in use may wish to break off the approach at a higher altitude, circle to land, and sequence in with the VFR traffic rather than do an approach to minimums to a different runway. To emphasize the potential for disaster, a recent midair fatality collision in Florida involved an aircraft on a VOR approach to runway 23 while other traffic was using runway 5 (AVweb.NewsWire, 1999).

If on a straight in approach to the active runway, instrument pilots should understand that they are operating contrary to the AIM and AC 90-66A and that failure to give way to other traffic established in the pattern could potentially result in civil action in the event of a collision (517 F. Supp. 825, 1981; 462 F. Supp. 674, 1979; 506 F. Supp. 728, 1979, 924 F. Supp. 1518, 1995). As shown in the cases involving instrument pilots making turns contrary to the active pattern (Yodice, 1995), pilots may be cited for failure to follow 14 CFR 91.126 (FAA, 1991), even if such turns are of a relatively small angle to final.

\section{CONCLUSION}

There are no substitutes for thorough preflight planning, good radio procedures, vigilance, and adherence to regulations. Why, then, would a pilot fail to follow the recommended procedures? Perhaps the pilot is trying to save time and money. Whatever the reason, failure to follow the AIM and advisory circulars as well as the regulations can cause confusion and lead to potential conflicts. In addition, the cases cited show that civil courts have established precedent regarding the need for adherence to the AIM and ACs. Until such time as the FAA publishes its new AC regarding traffic pattern entries at non-towered airports, pilots should comply with the AIM and existing ACs. The long way around to enter on the 45 may, in the long run, save the pilot considerable time and money from litigation. 


\section{REFERENCES}

Associate Aviation Underwriters and Fidelity and Casualty Company of New York v. United States of America, 462 F. Supp.674 (N.D. Texas 1979)

14 C.F.R. $\S$ 91.103, 91.113, 91.155. (2000, January 1). Washington, DC: U.S. Government Printing Office.

14 C.F.R. $\S$ 91.126. (1991, December 17). Washington, DC: U.S. Government Printing Office.

AOPA Air Safety Foundation. (1996). How to avoid a midair collision: a safety project of the AOPA Air Safety Foundation [pamphlet CO11-10/96]. Frederick, MD: Author.

AOPA Air Safety Foundation. (1998). 1998 Nall Report: Accident trends and factors. Frederick, MD: Author.

Duncan, P. -A. (n.d.). Staying the course. FAA aviation news [reprint of April, 1997 issue], 5-7.

Federal Aviation Administration. (1990, May 21). Traffic advisory practices at airports without operating towers (FAA Publication No. AC 90-42 F). Washington, DC: U.S. Government Printing Office.

Federal Aviation Administration. (1993, August 26). Recommended standard traffic patterns and practices for aeronautical operations at airports without operating control towers (FAA Publication No. AC 90-66A). Washington, DC: U.S. Government Printing Office.

Federal Aviation Administration. (1999, July 15). Aeronautical Information Manual. (43). Washington, DC: U.S. Superintendent of Documents;

In Re Greenwood Air Crash, No. IP93-9446-C-T/F, 924 F. Supp. 1518 (S.D. Indiana, 1995).

In Re N-500L Cases, Civ. No. 78-2126, 517 F. Supp. 825 (D. Puerto Rico, 1981), aff'd, 691 F.2d 15.

Jeppesen. (1999, August 13). Jeppesen Airway Manual Services, Northwest United States Airport Directory. (Washington, 10). Englewood, CO: Author.

Landsberg, B. (1997, April). Safety pilot: the great debate. [15 paragraphs]. AOPA Pilot. [On-line serial]. Available Internet: Hostname: aopa.org. Directory: asf/asfarticles/sp9704.html.

Mallen v. United States of America, 506 F. Supp. 728 (N.D. Georgia 1979), aff'd, 832 F.2d 1062.

National Transportation Safety Board. (2000). Available Internet: Hostname: ntsb.gov. Directory: aviation/SEA/93A168B.

National Transportation Safety Board. (2000). Available Internet: Hostname: ntsb.gov. Directory: aviation/CHI/00A066A.

Transport Canada. (1999, October 7). Aeronautical Information Publication. Canada (RAC 4.5). Ottawa, ON: Canadian Government Publishing.

Transport Canada. (1996, October 10). Canadian Air Regulations. (Subpart 2 Operating and Flight Rules). Available Internet: Hostname: tc.gc.ca. Directory: aviation/regserv/carac/CARS/cars/602e. 
Transportation Safety Board of Canada. (1997). Available Internet: Hostname: bsttsb.gc.ca. Directory: eng/stats/air.

Yodice, J.S. (1995). Pilot Counsel: straight-in approaches. [15 paragraphs]. AOPA Pilot. [On-line serial]. Available Internet: Hostname: aopa.org. Directory: members/files/pilot/1995. 


\section{Table 1}

Survey of 78 Flight Instructors

\section{Method of Entering Traffic Pattern from Opposite Side of Pattern \# of Respondents}

Overfly from upwind side at TPA +500 feet

Overfly from upwind side at TPA +1000 feet

Overfly from upwind side at TPA + other

Maneuver to enter on the 45 only

Upwind entry crossing near approach end

Other methods

Improperly filled out surveys

Note. Four respondents depicted both an overflight method and an upwind entry method 


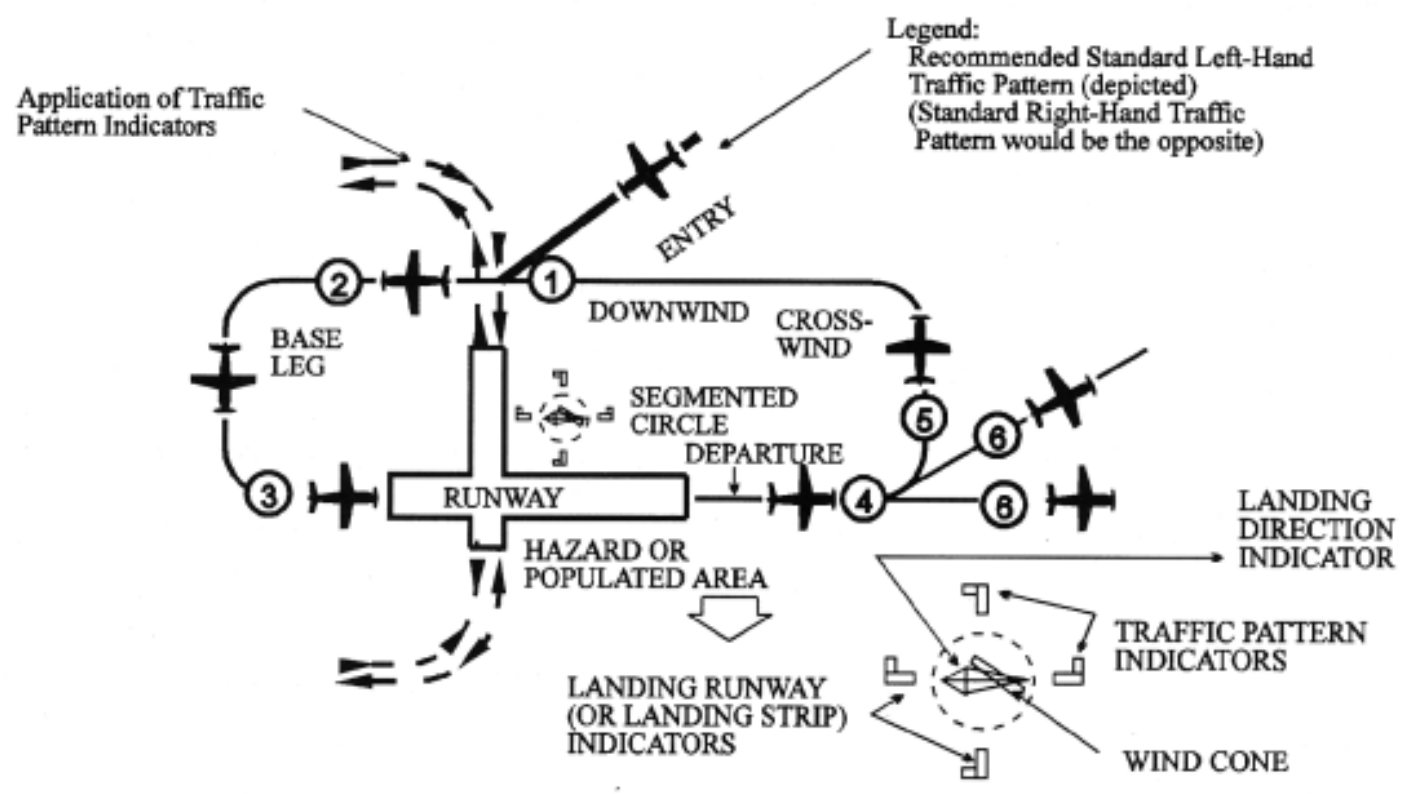

Figure 1. Traffic pattern operations single runway. From aeronautical information manual (section 4-3-4, figure 4-3-2), by Federal Aviation Administration, 1999, July 15, Washington, DC: Superintendent of Documents. 


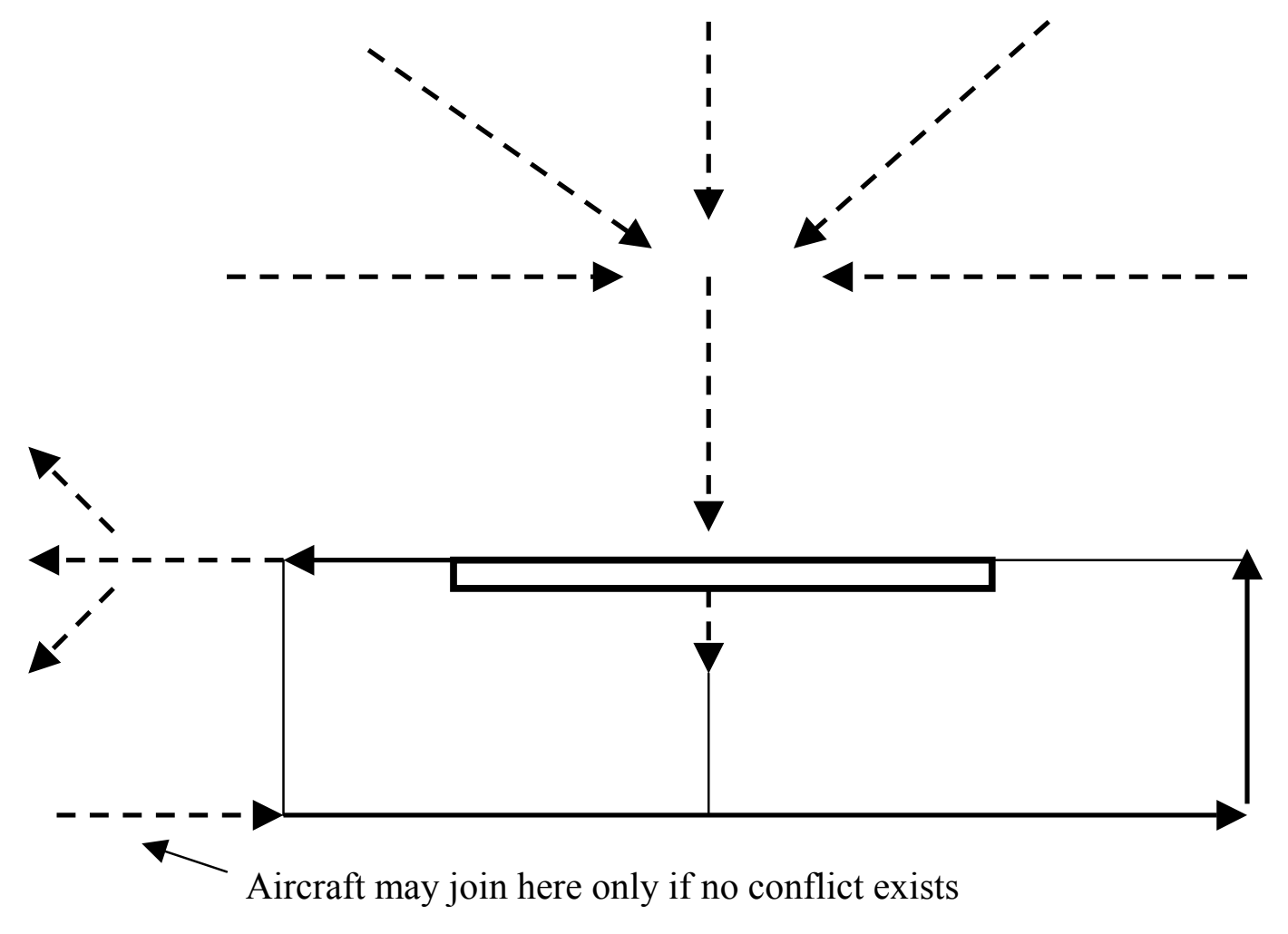

Figure 2. Standard left-hand circuit pattern. From aeronautical information publication (rules of the air, section 4.5.2, figure 4.6), by Transport Canada, 1999, October 7, Ottawa, ON, Canada: Civil Aviation Communications Centre. 
Figure 3. Overflight method to descend to TPA and enter on the 45 to downwind. Sloan, 2000.
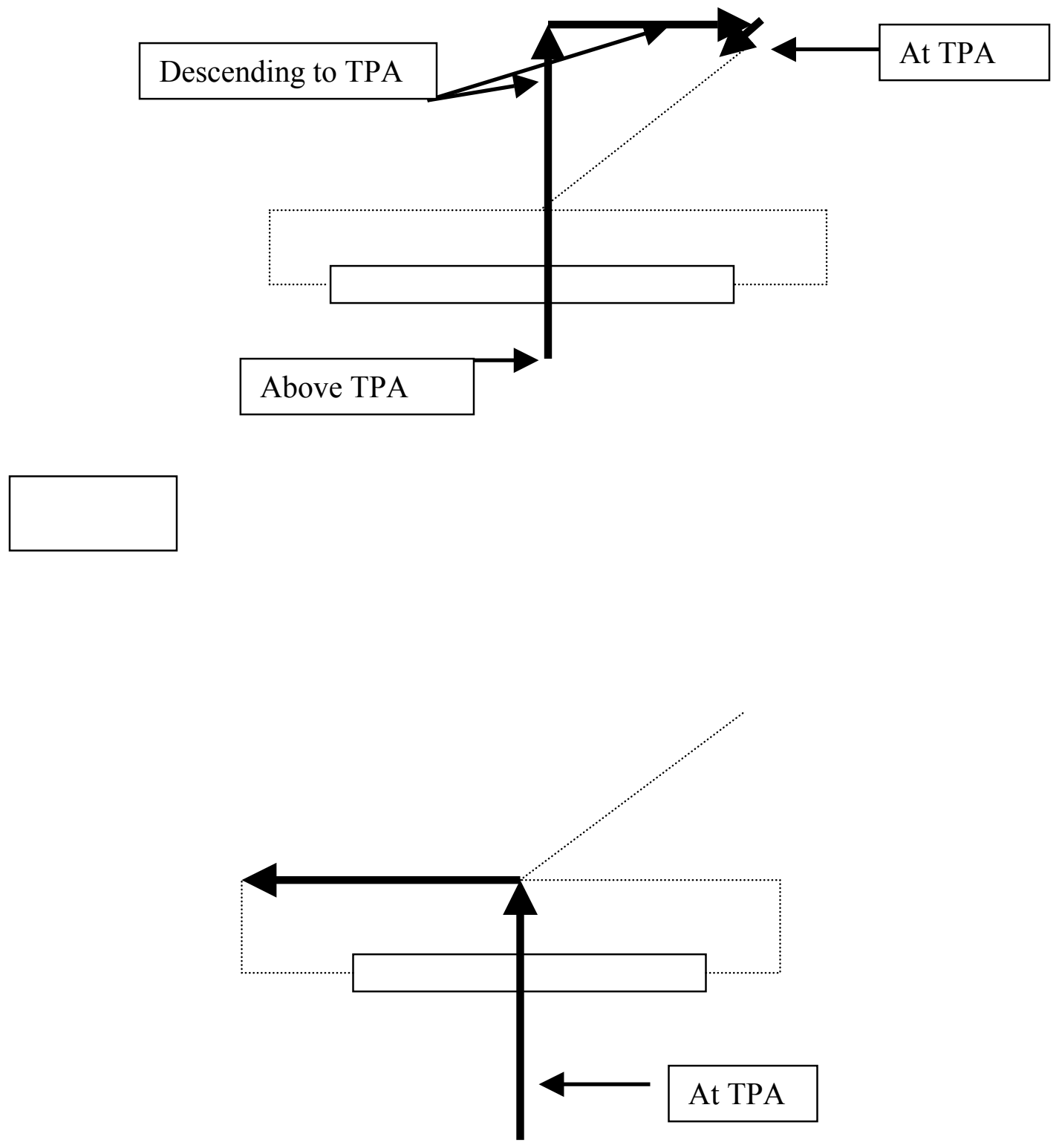

Figure 4. Upwind entry at TPA with turn to downwind leg. Sloan, 2000. 